\title{
O ELETROCHOQUE NO TRATAMENTO DAS DOENÇAS MENTAIS
}

\author{
A. C. PACHECO E SILVA \\ Professor de Clínica Psiquiátrica na Faculdade de Me- \\ dicina da Universidade de S. Paula e na Escola Paulista \\ de Medicina.
}

\section{HISTÓRICO}

Em 1902, Stephañé Leduc $(1,2,3)$, professor na Faculdade de Medicina de Nantes, publicou uma série de trabalhos, afirmando que as correntes elétricas teriam poderosa ação modificadora do psiquismo. Aquele autor sugeriu mesmo, baseado em experiências que realizou, o emprego da eletricidade para provocar o sono e até como meio anestésico. Logo depois, em 1903, BAttelli (4) notou a deflagração de crises epileptiformes provocadas pelas correntes elétricas industriais.

Em 1906, Robinovitch (5) propos o emprego de correntes elétricas com o objetivo de despertar o sono e ainda como meio seguro para o estudo da epilepsia experimental.

Em 1907. Prevost e Battelli (6) voltaram a tratar do assunto, realizando interessantes trabalhós relativos à ação da eletricidade sobre o sistema nervoso e à possibilidade de se produzirem crises convulsivas pela excitação elétrica da região motora.

Posteriormente, novas experiências foram levadas a cabo pelos fisiologistas, sem que, entretanto, os clínicos revelassem maior interesse pela questão.

Recentemente, porém, após o emprego da convulsoterapia pelo cardiazol, proposta por V MEDUNA, no tratamento da esquizofrenia, alguns investigadores aventaram a possibilidade de se recorrer à eletricidade como meio convulsivante, sem que fosse necessário se injetar uma substância química na corrente circulatória, cujos efeitos nem sempre seriam inócuos. Partindo daí, L. BINI (7) iniciou as suas pesquisas, lançando mão, a princípio, de uma técnica ideada por VIALE. Fez, assim, passar uma corrente alternante de 120 volts através do corpo de um animal, colocando um eletrodio na boca é 
outro no reto, pelo espaço de 0,15 a 0,20 de segundo. Com esse processo, BinI logrou provocar crises convulsivas típicas; entretanto, notou que tais correntes provocavam alterações no sistema nervoso, razão por que buscou outra técnica para obter os mesmos resultados, sem os inconvenientes apontados.

\section{PRIMEIRAS EXPERIÊNCIAS COM O ELETROCHOQUE}

Logo depois, Binr publicava, em colaboração com o Prof. CER= LETTI (8), novos trabalhos, afirmando ter descoberto um novo pro- cesso elétrico capaz de deflagrar convulsões sem dano para o sistema nervoso. Nesses estudos, apresentados à Academia de Medicina de Roma, em maio de 1938, aqueles autores reuniram algumas observações que thes permitiram concluir ser esse método, por eles denominado de eletrochoque, tão bom quanto o tratamento pelo cardiazol, com a vantagem de não produzir as desagradaveis sensações subjetivas percebidas pelos pacientes tratados pelo processo de V. Meduna.

O aparelho, construido por BINI e utilizado para as aplicações do eletrochoque, compreende dois circuitos 'diferentes. O' primeiro é um circuito de baixa voltagem para medir a resistência elétrica da cabeça do doente. O segundo circuito é uma corrente alternante de 50 períodos, cuja voltagem pode variar de 50 a 150 volts e cuja intensidade pode se elevar até 2.000 miliamperes. Um dispositivo especial regula a corrente de forma a permitir a sua passagem durante um tempo muito cúrto, de um a cinco décimos de segundo. Os eletrodios, de prata, recobertos de tárlatana, embebidos em água salgada, são aplicados nas têmporas e aí mantidos por uma cinta elástica.

O método não tardou a ser empregado, com sucesso, por outros psiquiatras italianos, aparecendo logo trabalhos a respeito na Inglaterra, onde Fleming, Gola e Grey (9) o utilizaram com resultados muito favoraveis.

Os pesquizadores americanos passaram tamben a empregar o eletrochoque como meio convulsivante. Em 1939, após pacientes estudos, JoSEPH Hughes, chefe do departamento de investigações do Pennsylvania Hospital, construiu o primeiro aparelho fabricado nos Estados Unidos, adotando, em suas linhas gerais, o esquema de CERLETTI e BINI, mas introduzindo algumas modificações que permitiam maior segurança nas aplicações, sobretudo no tocante à regulação do tempo da corrente.

Os primeiros experimentos realizados por Hughes, em colaboração com L. Smith e Donald W. Hastings (10), foram feitos em gatos, cujos cérebros foram, depois cuidadosamente examinados, não tendo sido encontradas lesões histo-patológicas. Isso os animout a empregar o eletrochoque em alguns doentes, tendo logo observado não só que o processo oferecia certas vantagens sobre o cardiazol, como ainda obtiveram resultados surpreendentes em certos casos. 
Os psiquiatras americanos se mostraram logo entusiasmados com o novo processo convulsivante, recorrendo a vários laboratórios de eletro-técnica para a construção de aparelhos de vários tipos, destinados à produção do eletrochoque.

\section{RESULTADOS OBTIDOS PELOS AUTORES AMERICANOS}

No 97. Congresso Anual da American Psychiatric Association, realizado em maio deste ano, na cidade de Richmond, ao qual estivemos presente, uma das sessões foi inteiramente dedicada ao tratamento pelo eletrochoque. Numerosos foram os trabalhos apresentados sobre a questão, destacando-se alguns que vamos resumir.

Smith, Hughes, Alpers e Hastings chegaram às seguintes conclusões : dioso.

$1^{\circ}$ - O tratamento pelo eletrochoque é simples e pouco dispen-

$20^{\circ}$ - O paciente não acusa o menor incômodo, visto como o tratamento não é, em absolutó, doloroso, e há perda completa da memória no que se refere à aplicação.

3. - O período convulsivo é menos severo que o observado com o cardiazol.

$4 .^{\circ}$ - As fraturas e as luxações não ocorrem tão frequentemente, a julgar pela nossa experiência em vários casos.

5. ${ }^{\circ}$ - Os pacientes acusam melhoras prontas logo no início do tratamento.

6. - Não há necessidade da introdução de drogas pela via parenteral.

O Prof. Abraham Myerson (11), de Boston, preconizou o - tratamento em ambulatório, nos casos de psicose maníaco-depressiva, iniciañdo-se por aplicações repetidas, tres por semana, espaçando-se ao depois de $8 \mathrm{em} 8$ dias, à medida que o paciente vai melhorando. Obteve, assim, o restabelecimento de 15 doentes no espaço de 4 meses, tendo empregado o método sem acidentes em 50 pacientes.

H. Löwenbach e E. J. Stainbrook (12), do Duke University Hospital, chegaram a conclusões mais ou menos análogas.

L. Kalinowsky e W. A. Horwitz (13), do New York State Psychiatric Institute, abordam o problema dos resultados obtidos àpenas com reações menos intensas, por meio de correntes mais fracas e de menor duração, de forma a provocar somente equivalentes psíquicos ou pequenas reações motoras, semelhantes às do "pequeno mal".

O Prof. Victor E. Gonda (14), de Chicago, apresentou tam: bem os resultados das suas investigações, consubstanciados nas seguintes conclusões :

$10^{\circ}$ - O método elétrico convulsivante para o tratamento da esquizofrenia e das psicoses afetivas foi descrito. 
2..$^{\circ}$ - O autor descreve a convulsão elétrica induzida, destacando o fato da ausência da dor e de qualquer receio por parte do doente, em contraste com os demais métódos.

3. ${ }^{\circ}$ - A completa ausência de dor e amnésia do tratamento ficaram comprovadas.

$4 .^{\circ}$ - O autor expreśsa a opinião de que as convulsões são menos severas e que um menor número de complicações são verificadas, sendo mais facil prevení-las.

$5 .^{\circ}$ - O resultado benéfico obtido em 40 casos tratados, num total de 612 convulsões, demonstrou serem os resultados melhores que os obtidos com outros tratamentos convulsivantes.

6..$^{\circ}$ - A importância da psicoterapia em combinação com as convulsões foi salientada.

\section{A NOSSA EXPERIENCIA PESSOAL}

Depois da realização do Congresso de Richmond, tivemos ensejo de visitar vários hospitais psiquiátricos americanos, assistindo a aplicações do eletrochoque nos seguintes hospitais: The Tucker Sanatorium (Richmond), Serviço do Dr. R.' Howard Masters, The Doctor Hospital (New York), Serviço do Prof. Foster Kennedy, Chicago Eook Country (Serviço do Prof. NeymanN), Boston State Hospital (Serviço do Dr. Purcell G. Shúbe).

Adquirimos dessas observações a convicção, sobretudo depois de ouvir tambem a opinião insuspeita e autorizada do nosso eminente amigo $\mathrm{V}$ Meduna, de que o eletrochoque representa um grande passo na terapêutica psiquiátrica.

De acordo com os conselhos dos colegas americanos, adquirimos dois aparelhos, um da Casa Offner Electronics, de Chicago, e outro dos laboratórijos Rahm Instruments Inc., de New York, afim de empregarmos o novo método convulsivante.

Nos primeiros dias de julho do corrente ano iniciámos as nossas primeiras aplicações do eletrochoque, tendo antes tomado as necessárias precauções para a calibragem do aparelho e a verificação do seu exato funcionamento.

Iniciámos a aplicação do eletrochoque simultaneamente em doentes da Clínica Psiquiátrica da Faculdade de Medicina de São Paulo, da Sanatório Pinel e do Sanatório Esperança.

Conquanto a voltagem da energia elétrica da cidade de S. Paulo fosse exatamente idêntica à da maioria das cidades americanas, isto é, 115 volts, 50 ciclos, e os aparelhos adquiridos estivessem calibrados para aquela corrente, julgamos prudente iniciar as nossas primeiras aplicações em animais. Os resultados foram inteiramente satisfatórios, pois as convulsões epileptiformes deflagraram com rapidez logo após o choque, seguindo-se um estado crepuscular com amnésia, pois verificámos ter o cão ficado desorientado após a crise convulsiva. Passada a fase post-convulsiva, o animal recuperou o seu es- 
tado anterior, mostrando-se docil e revelando completa amnésia do que ocorrera, tanto assim que foi possivel submetê-lo a choques sucessivos, sem que acusasse o menor receio. Verificada, assim, a inocuidade do método, passámos, em seguida, a aplicá-lo nos doentes com eletrocardiograma normal e que já tinham sido submetidos anteriormente à convulsoterapia pelo cardiazol.

\section{TECNICA}

Adotámos, em suas linhas gerais, o critério seguido pelos autores americanos, os quais, entre as contraindicações, incluem as se- guintes:

As más condições físicas gerais. A artério-esclerose avançada. As cardiopatias. A tuberculose. As tromboflebites, tanto agudas como crônicas. As afeç̧ões renais. Os tumores malignos. As lesões ósseas e articulares e finalmente - a epilepsia ơ equivalentes na história clínica do paciente.

O doente deve estar em jejum e vestir pijama folgado, exatamente como se procede quando se pratica a convưulsoterapia pelo cardiazol:

Os autores americanos costumam colocar, para prevenir fraturas das vértebras, pequenos sacos de areia ou um travesseiro duro, em correspondência à convexidade dorso-lombar, o que, aliás, tambem fazem quando aplicam o cardiazol. O paciente deve ser colocado num sofá estofado de madeira, que por sua vez deve se encontrar sobre $\mathrm{o}$. soalho ou sobre um linolejum, nunca sobre o ladrilho ou cimento. Sobre o divan convem colocar um lençol de borracha e sobre este um de algodão, completamente seco. E' preciso tomar todas as precauções para impedir a passagem da corrente através do coraçã̃o do paciente.

Os eletródios são colocados um de cada lado da cabeça do paciente, na região fronto-parietal. A. Bingel e F. MEGGENDORFER (15), autores alemães, recomendam a raspagem dos cabelos da região onde são colocados os eletródios, o que contribue para diminuir a resistência.

Estes são mantidos por uma cinta de borracha perfurada. Certos autores usam eletródios diferentes, que comprimem a cabeça por meio de molas colocadas num compasso especial, os quais têm nas extremidades duas bonecas de metal revestidas por flanela.

Antes de se aplicarem os eletródios, unta-se a região onde vão ser colocados com uma pasta especial. (Electrode Jelly) para favorecer o contacto. A flanela que reveste os eletródios é embebida numa solução saturada de cloreto de sodio. Entre as arcadas dentárias do paciente se coloca um chumaço de gaze torcida, para proteger os dentes e se evitar a mordedura da língua ou dos labios.

Um dos operadores deverá calçar luvas de borracha para segurar, sem perigo, a cabeça do doente, no momento da passagem da 
corrente, si tal for necessário. Os demais não devem tocar no corpo do paciente no momento do choque.

$O$ aparelho deve ser ligado numa corrente alternante de $50-60$ ciclos, 110-120 volts e nunca na corrente direta.

- O potencial é ajustado em 90 volts, que é em geral o mínimo necessário para se produzir uma convulsão.

$\mathrm{O}$ medidor de décimos de segundo deve ser fixado em $1 / 10$ a $2 / 10$ inicialmente.

Antes de se aplicar o tratamento, mede-se a resistência do paciente, que varia habitualmente, nesse circuito, entre 500 e 1.200 ohms.

O tempo de passagem da corrente, o potencial e a resistência do paciente produzem a necessária miliamperagem. Um mínimo de 250 miliamperes são necessários para produzir uma convulsão. Em regra, há necessidade de mais de 250 miliamperes, poìs doentès há que resistem até 800 miliamperes.

$\mathrm{Na}$ prática, os psiquiatras americanos iniciam o tratamento com 400 miliamperes, utilizando uma corrente de 100 volts, com a duração de 20 centésimos de segundo. No caso da convulsão não deflagrar, a mesma corrente é mantida, mas o tempo de passagem é auméntádo de 20 para 30 centésimos de segundo. Si, ainda assim, não 'se obtiver o resultado desejado, o tempo é elevado para 40 centésimos de segundo. Si falhar a crise, a voltagem é elevada para 110 , voltando-se a aplicar apenas 20 centésimos de segundo, para depois aumentar de novo o tempo de passagem da corrente, no caso do paciente não apresentar convulsões.

\section{EFEITOS DO ELETROCHOQUE}

Crise frusta. - Com as correntes fracas, ou nos doentes extremamente resistentes, verifica-se uma crise abortada, a que os americanos denominam "missed convulsion". O paciente se mostra conciente logo depois da crise, mas un tanto obnubilado. Responde às perguntas com certo retardo na marcha do pensamento, acusando leve amnésia do tratamento. Nesta crise frusta não se notam movimentos convulsivos; apenas o corpo é agitado por um forte abalo que vai da cabeça aos pés. Quando tal se verifica, deixa-se o. paciente em repouso de 3 a 5 minutos, para se fazer nova aplicação, com a mesma corrente, mas aplicada por maior tempo. No caso do tempo ter já alcançado perto de meio segundo, aumenta-se a corrente em 10 volts.

Equivalente convulsivo. - Ao receber o choque, o paciente tem uma crise tônica, empalidece, distende fortemente os membros, inclina-se para a frente como se quisesse sentar-se, diz palavras ininteligiveis, abre desmedidamente os olhos, que permanecem fixados, faz frequentes movimentos de deglutição. Alguns segundos depois, os músculos se relaxam, mas um tremor fino agita os membros do pa- 
ciente, que nessa fase se mostra inteiramente, inconciente e desmemóriado. Durante um período variavel entre 5 e 20 minutos, o doente se mostra amnésico, obnubilado, confuso e desorientado e não raro com leve disartria. Tal reação deve ser considerada como eficiente, não sendo aconselhavel a aplicação de novo choque nesse dia, muito emblora alguns autores costumem aplicar repetidos choques, até alcançarem francas convulsóes. Tal crise pode ser comparada à do pequeno mal.

Crise convulsiva. - Ao receber o choque, o paciente entra imediatamente em convulsão, idêntica à que se observa nos casos de epilepsia genuina ou na provocada pelo cardiazol. Em certos casos, a crise sobrevem 20 a 30 segundos após a aplicação da corrente.

A fase tônica é mais rápida com o eletrochoque que com os meios convulsivantes; o paciente não tarda a entrar logo no período clônico. Esse fato é considerado de grande vantagem, sobretudo tendo em conta o fato das fraturas se verificarem no período tônico.

$\mathrm{Na}$ fase convulsiva, após rápida palidez, o paciente se torna bastante cianótico. A impressão de vários pesquizadores, de ser a cianose mais intensa e a fase de apnéia mais duradoura no eletrochoque, é tambem a nossa. A cianose não se limita à face, mas se estende ao pescoço e ao peito, notando-se tambem nas mãos. A secreção salivar é abundante, sendo aconselhavel que se coloque o doente, logo após a fase convulsiva, em decúbito lateral direito, de forma a facilitar o escoamento da saliva, afim de se evitarem complicações pulmonares provocadas pela aspiração.

A ejaculação, tão frequente na convulsoterapia pelo cardiazol, é raramente observada após a aplicação do eletrochoque. O mesmo se dá com relação aos vômitos.

A emissão de urina, conquanto não se verifique habitualmente, não constitue exceção, sobretudo quando não se tem o cuidado de fazer o doente, antes de se submeter ao tratamento, esvasiar a bexiga.

Após a fase convulsiva, o paciente permanece em estupor, respirando profunda e ruidosamente. Após 10 minutos a uma hora e meia, conforme o doente e num mesmo doente de acôrdo com a intensidade da crise, recupera o paciente, gradativamente, os sentidos. O despertar é calmo e o doente se mostra bem humorado. Segue-se um sono profundo e tranquilo, que se prolonga por duas ou mais horas. Num đoente que, após a convulsoterapia pelo cardiazol, se mostrava sempre extremamente agitado, notámos leve excitação motora. Após a aplicação, o paciente se debate por alguns segundos, acalmando-se imediatamente depois de concitado a cessar tais movimentos.

A amnésia é, a princípio, total. A memória vai, aos poucos, se restabelecendo para os fatos passados. Entretanto, o tipo retroanterógrado da amnésia é característico, pois que o paciente não se recorda absolutamente dos acontecimentos ocorridos antes, durante 
e depois da aplicação. Aos poucos, vai depois recuperando a lembrança dos fatos, valendo-se, frequentemente, do concurso dos presentes para reavivar os fatos esquecidos.

A amnésia do tipo lacunar perdura, por veześ, de algumas horas a alguns dias.

Jamais verificámos, e nisso consiste, ao nosso ver, a maior vantagem do eletrochoque, o chamado pânico cardiazóliço. Todos os pacientes são unânimes em preferir o eletrochoque ao tratamento pelo cardiazol, revelando a mais absoluta áversão por este último método terapêutico.

Um dos nossos doentes, cujos sintomas psíquicos haviam regredido com o cardiazol, mas que ameaçavam reincidir, foi por nós submetido ao eletrochoque, com grande sucesso. Tratava-se de um rapaz inteligente e culto, que se mostrou logo entusiasta do novo tratamento, a ponto de procurar um companheiro que tambem necessitava da terapêutica convulsivante, mas que a abandonara pelo pavor que a aplicação do cardiazol the inspirava, para que se submetesse tambem ao eletrochoque.

Eis como o paciente resumiu as suas impressões:

Impressões do cardiazol. - Na primeira aplicação de cardiazol tive convulsões com a impressão de morte, mas suportei porque perdi os sentidos. Quando recuperei os sentidos, tive amnésia completa e sentia dores no corpo como se estivesse contundido. A segunda injeção foi equivalente e tive conciência de tudo. Senti uma angústia indescritivel. As ameaças de choque davam-me sensação de morte. $\mathrm{Vi}$ ć́rculos vermelhos ao redor dos olhos e o enfermeiro que me assistia parece que subia ao teto e se tornava flúdico. Vi todos os movimentos do médico e do enfermeiro. Passadas as crises, ainda conservei as horriveis impressões e à noite, nos sonhos, senti a repetição da angústia do cardiazol. O cheiro da injeção, senti-o em todos os lugares durante os dias seguintes à aplicação. Criei verdadeiro pavor pelo cardiazol e na terceira aplicação, embora sabendo que aquela medicação iria me ser benéfica, não tive coragem. Debalde foram as instâncias dos srs. médicos e do enfermeiro. Não tomei o cardiázol e mesmo uma injeção de cálcio e bromoformina que quiseram me injetar, devido ao meu estado de excitação nervoša, tomei-a de pé, temendo que fosse cardiazol.

Impressões do aparelho de eletrochoque. - Quando vi $\backslash$ o aparelho de eletrochoque, lembrei-me das angústias causadas pelo cardiazol e faltou-me a coragem para me submeter ao choque. Não duvidei das palavras dos srs. médicos quando me afirmaram que a vantagem do aparelho sobre o cardiazol era justamente porque este não produzia aquela angústia de morte, mas o pavor cardiazólico impediu-me de cooperar com eles. No dia seguinte voltei mais calmo e me submeti pacientemente ao tratamento. Depois dos preparativos técnicos apertei um guardanapo entre os dentes e esperei,- $\mathrm{O}$ choque 
veio inesperadamente, choque forte que me fez perder os sentidos. Não senti nenhuma angústia/ como a produzida pelo cardiazol. Despertei noutra cama com amnésia. Aos poucos fui recuperando a memória e não guardei nenhuma má impressão do choque. Ao contrário do que acontecia quando tomava cardiazol, tive bom humor e pensei logo em submeter-me à segunda aplicação do eletrochoque. Senti muita melhora no meu estado.

\section{COMPLICAÇõES}

As complicações são as mesmas que ocorrem no tratamento pelo cardiazol - fraturas, arrancamentos de tendões, mordeduras da língua e dos lábios, cefaléia, etc. Não foram até aquí registradas complicações pulmonares - abcessos ou gangrenas - o que confirma a hipótese aventada por ZEIFERT, segundo o qual as injeções intravenosas de cardiazol provocam embolias, as quais acarretariam as supurações pulmonares.

Num dos pacientes por nós tratadós verificámos uma fase de apnéia, com cianose da face, pescoço e mãos, assaz duradoura. Entretanto, a pausa respiratória cessou logo após a tração da língua e algumas manobras de respiração artificial. $O$ paciente recuperou a conciência cerca de 40 minutos após a crise, sem acusar, nas horas ou nos dias subsequentes, qualquer distúrbio. $\mathrm{Em}_{\mathrm{m}}$ tal emergência, G. Sogliani (16) recomenda o emprego de injeções de lobelina e de cafeina, afim de excitar os centros respiratórios, suspendendo-se o tratamento, dada a reprodução dos mesmos fenômeņos observada nas aplicações subsequentes.

Os autores italianos, bem como os ingleses e americános, jamais notaram, como ficou dito, desordens cardíacas no decurso do eletrochoque, fazendo apenas referência a ligeira taquicardia consequente ao esforço físico provocado pelas convulsões. Todåvia, quer-nos parecer medida de prudência não se aplicar o eletrochoque senão em doentes possuidores de eletrocardiograma normal ou com leves modificaçôes, que, a juizo de um cardiologista, não contraindiquem "o tratamento.

\section{RESULTADOS}

Submetemos até esta data 21 doentes a tratamento pelo eletrochoque, tendo aplicado um total de 139 choques. Desses 21 pacientes, 16 eram esquizofrênicos e 5 melancólicos. Dos 16 esquizofrếnicos, 5 se encontram em remissão total, 3 em remissão parcial, 4 apreseritaram evidentes melhoras e continuam em tratamento; os restantes, esquizofrênicos crônicos, permanecem estacionários. Dos melancólicos, 2 tiveram remissão total, tendo obtido alta; 1 iniciou o tratamento há poucos dias, mas já acusa melhoras; num caso obtivemos algumas melhoras após as 3 primeiras aplicações, seguidas de recaida no estado anterior. 


\section{MECANISMO DA ELETROCONVULSÃO}

Numa excelente mise aiu point.da questão, ANDRé Plichet (17) faz interessantes comentários sobre este aspecto do problema, concluindo ser o mecanismo dessa crise ainda obscuro. Pondera, todavia; que, segundo as teorias de Lennox, a epilepsia deve ser considerada como a expressão clínica de uma disritmia elétrica dó cérebro. O estudo dos eletroencefalogramas dos epiléticos mostra variações na frequência, na forma das ondas elétricas produzidas por um cérebro normal.

Convem notar, diz Plichet, que a melhor forma de se produzirem convulsões elétricas está na aplicação dos eletródios em correspondência da parte média da primeira e segunda circunvoluçôes frontais. Ora, é a esśa żona que Foerster confere uma importância especial na produção da epilepsia. Esta zona, nos epiléticos esśenciais, contem, frequentemente, um foco de ondas lentas registradas pelo eletroencefalógrafo. A passagem de uma corrente alternante de 50 períodos nessa zona, em um tempo relativamente curto, coloca o cérebro de um indivíduo não epilético nas mesmas condições elétricas ou eletrônicas daquelas em que se encontra o cérebro de. um epilético. O primeiro reage então como o segundo.

Em conclusão: O eletrochoque representa, indiscutivelmente, um recurso poderoso no tratamento des doenças mentais e um grande passo para obviár os inconvenientes da convulsoterapia pelas substâncias químicas, razão que nos lévou a relatar aos nossos colegas a técnica e os resultados das primeiras observações feitas no Brasil, e quiçá na América do Sul, com o referido método terapêutico.

\section{BIBLIOGRAFIA}

1 - Leduc St. - Comptes Rendus de la Academie Scientifique. 21-VII-1902.

2 - LEDUC ST. - La Biologie Synthetique.

3 - LEDUC St. - L'Energétique de la vie.

4 - Battelli - Production d'accés épileptiformes par les courants électriques industriales - Comptes Rendus de la Société de Biologie - 55.903 - 1903.

5 - Robinovitch L. G. - Sommeil éléctrique. Epilepsie électrique et électrocution. Editora Dugas. Nantes, 1906.

6 - PRevost E Battelli - Expériences relatives à l'épilepsie experimentale. Revue Neurologique - $15.914-1907$.

$7 \rightarrow$ L. BINI - Ricerche sperimentali nell'acesso epileptico da corrente eletrica. Schweiz. Archiv. Neurolog. und Psychiatr. 39 Ergamzgsh. 121.

8 - Cerlettri U. e Bini L. - L'Elettroshock. Arch. General Neurologia, Psichiatria e Psichoanalisi - 19.3 - 1938

9 - Fleming, F. L. Gola and W. GRey - Eletric Convulsions Therapy of Schizophrenia - The Lancet 2:1353 - 1939.

10 - L. H. Smith, J. Hughes, D. W. Hastings - First Impressions of Eletroshock Treatment - The Pennsylvania Medical Journal - January - 1941 . 
11 - Abraham Myerson - The Out-Patient Eletric Shock. Treatment of Maniac-depressive Psychoses - $97 .^{\circ}$ Congresso da American Psychiatry Association - Richmond - 1941.

12 - H. Löwenbach M. D. e E. J. Staingrook - Observations of Mental Patients After Electroshocks - 97. ${ }^{\circ}$.Congresso da American Psychiatry Association - Richmond - 1941.

13 - L. Kalinowsky e W. A. Horwitz - "The Petit Mal". Reponse in Electric Shock Therapy; Its Theoretical and Therapeutic Significance. 97. ${ }^{\circ}$ Congresso da American Psychiatric Association. Richmond 1941.

14 - VICTOR E. GONDA - Treatment of Mental Diseases with Electrically System. Vol. II - N. ${ }^{6} 3$ - March 1941.

15 - Bingee, A. u. Meggendorffer, F. - Über die ersten deutschen Versuche einer Elektro-Krampfbehandlung der Geiteskrankheiten. - Psychiatr. Neurol. Wschrift 42 n. ${ }^{\circ} 5: 41-43$. Febr. 1940.

16 - G. Sogliani - Eletroshockterapia e Cardiasol-Terapia - Rassegne di Studi Psichiatrici. Vol. XXVIII fasc. 4 Luglio-Agosto 1939' (XVII.०).

17 - ANDRE Plichet - L'életrochoc - Le traitement des affections mentales par les crises convulsives électriques. "La Presse Médicale", N. . 91-92 - 20-23 Novembro 1940.

\section{o departamento de}

\section{ADMINISTRAÇ $\tilde{A} O$ \\ PREDIAL}

\section{DA}

\section{Caixa Geral de Emprestimos}

Regularizará e augmentará o rendimento dos predios de $V$. S.

Idoneidade absoluta

Prestação rigorosa de contas

\section{Caixa Geral de Emprestimos}

Caisse Générale de Prêts Fonciers et Industriels

R. Tabatinguera, 164 - Fone 2-4722 - SÃO PAULO 


\section{PYORRHÉA}

Gengivas sangrentas, dentes abalados e mau halito: Resultados positivos em 8 dias, com o especifico PYORRHON.

CONSULTAS: $30 \$ 000$.

DEMONSTRAÇõES PRATICAS AOS SENHORES MEDICOS E DENTISTAS.

\section{DR. CLINEO PAIM}

Rua Barão de Itapetininga, 120 5. andar :- Salas, 505 e 506 (Casa Guatapará)

Tel: 4-4050 - SÃO PAULO

ENDOSCOPIOS

PARA TODOS

OSCASOS DE

DIAGNOSTICA

E CIRURGIA

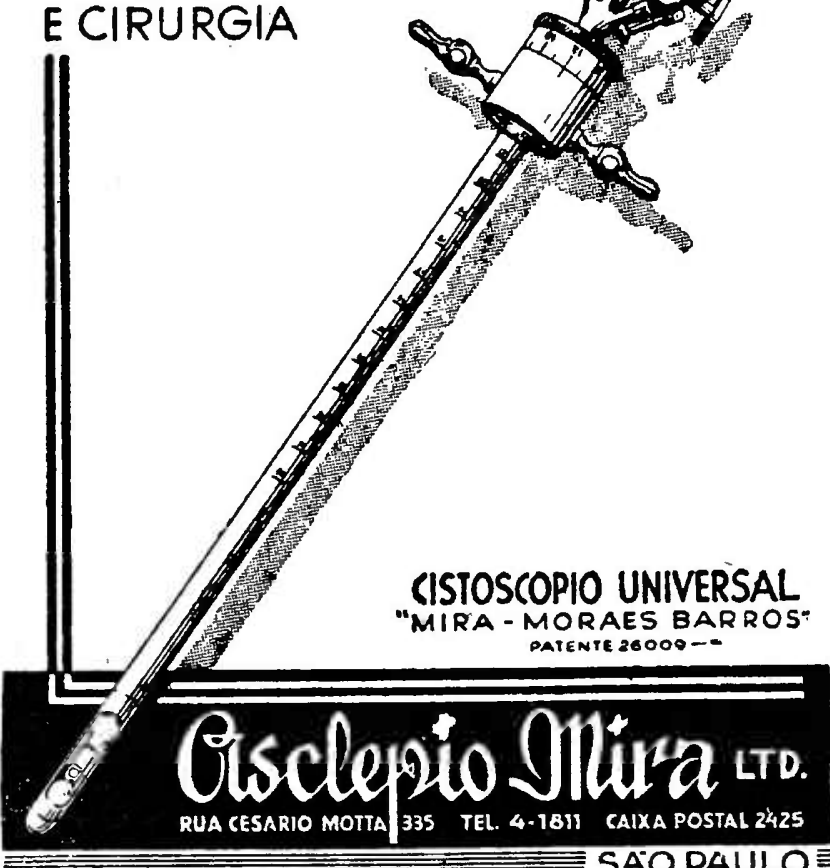

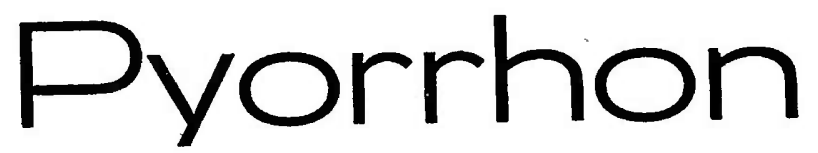

Um medicamento que veio resolver os casos de Gengivites e Pyornéa

\section{A T E S T A D O}

E' para mim um prazer atestar que venho empregando em minha clinica com os mais brilhantes resultados, o Pyorrhon, medicamento de escol para o tratamento da Piorrhéa Alveolar e das Gengivites.

Tambem venho calorosamente recomendando o seu uso aos meus pacientes, porque assim fazendo estes teem assegurada a perfeita saude do seu meio bucal.

o Pyorrhon é um preparado que pela propaganda honesta com que é lançado e pelos seus meritos, merece da nossa classe a melhor acolhida.

São Paulo, 6 de Outubro de 1939.

Octavio Demacq Rosas. 


\section{DEXTROSOL}

(GLUCOSE-d)

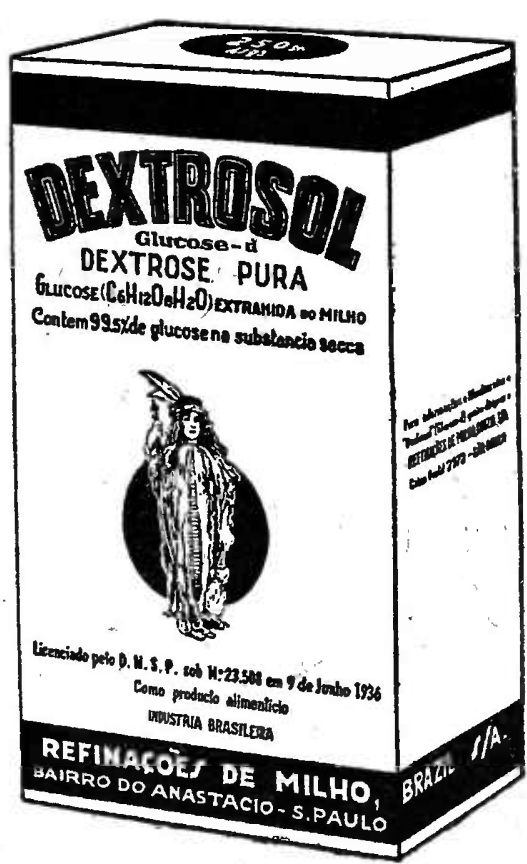

"DRENA AGUA dOS TECIDOS PARA A CIRCULAÇÃO, ELIMINANDO EDEMAS, AUMENTANDO O VOLUME SANGUINEO E PROMOVENDO A DIURESE"

E. MEYER - Usos Terapeuticos das Injeções Endovenosas de Soluções de Glucose) Zentralb. f. klin., Med. 102.343, 1925. Abst. J. A. M. A. 86.52I, 1926. 


\section{SYNCORTYL}

Hormonio cristalizado do cortex adrenal

(acetato de desoxicorticosterona)

Ampolas a 2, 5, 10 mgrs.

\section{LUTOGYL}

Hormonio cristalizado do corpo amarelo (Progesterona)

Ampolas a 5 e 10 mgrs.

\section{MINISTA}

Hormonio tecidual neurotropo

(Bicloridrato de histamina)

Ampolas para uso intradermico

Linimento para uso percutaneo

\section{LABORATORIOS:}

Silva Araujo Roussel S/A

FILIAL EM SÃO PAULO - RUA 25 DE MARÇO, 179

Fone $\quad 2-6935$ 